\title{
X-ray Transitions in Highly Charged Neonlike Ions
}

P. Beiersdorfer, S. von Goeler, M. Bitter, E. Hinnov, R. Bell, S. Bernabei, J. Felt, K. W. Hill, R. Hulse, J. Stevens, S. Suckewer, J. Timberlake, and A. Wouter Princeton University, Plasma Physics Laboratory, Pr nceton, New Jersey 08544. USA

M. H. Chen, J. H. Scofield, D. D. Dietrich. M. Gerassin enko, E. Silver, and R. S. Walling University of California, Lawrence Livermore National Laboratory, Livermore, Califormia 94550, USA

P. L. Hagelstein

Massachussettes Institute of Technology, Research of Laboratory Electronics, Cambridge, MA 02139

\section{Abstract}

Wavelength measurements of $n=3$ to $n=2$ transitions in neonlike $\mathrm{Xe}^{4+4}$, $\mathrm{La}^{47}, \mathrm{Nd}^{50+}$, and $\mathrm{Eu}^{53+}$ have been made using a high-resolution Bragg-crystal spectrometer on the Princeton Large Torus tokamak. The measurements cover the wavelength regions $2.00-3.00 \mathrm{~A}$ and include the electric dipole, and the electric and magnetic quadrupole transitions. The measured wavelengths are compared $t$, coergy levels obtained from a multiconfigurational Dirac-Fock calculation. Systematic differences between the experimental and theoretical values are found, which vary smothly with atomic number. The magnitude of the differences depends on the particular type of transition and ranges from $-2.8 \mathrm{eV}$ to $+2.2 \mathrm{eV}$. Inclusion of electron correlation corrections due to ground state correlations and (super) Coster-Kronig type fluctuations in the therretical energies is shown to reduce the differences for some but not all types of transitions. 


\section{Introduction}

The spectra of very highly charged ions can provide detailed information on the structure of multi-electron systems in a strong Coulomb field. Therefore, high-resolution wavelength measurements of spectral lines emitted from few-electron, high- $Z$ systems can be used to check the accuracy of multiconfigurational relativistic atomic structure calculations.

Systematic comparisons betwcen experimental and theoretical transition energies have been made recently by Seely et al. For $t p \rightarrow$ ts transitions in copperlike ions and for $3 d \rightarrow 3 p$ transitions in robalilike ions for elements up to uranium. ${ }^{\prime}$ In the case of the colbaltlike transitions the comparison between experimental observations and theuretical salues from Dirac-Fock calculations showed a discrepancy of about $3 \mathrm{el}$. This discrepancy has since bern remored by including electron correlation corrections to the theoretical transition ensrgies. ${ }^{2}$

High-resolution data on $\Delta n=1 \mathrm{x}$-ray transitions in multi-elect ron systems such as the $3 \rightarrow 2 x$-ray transitions in neonlike systems bave been wijtained only recently, and the existing data show some disagreement with theoretical wavelengths. A high-resolution measurement of the $3 \rightarrow 2$ transitions in neonlike silver has been made on the Princeton Large Torus (PLT) ${ }^{3}$ The measurements showed systematic discrepancies between olsserved and calculated wavelengths which depended on the type of transition. It was found that the experinental wavelengths of the $3 p, 3 s \rightarrow 2 p$ transitions were slorter than the values predicted by a relativistic atomic structure calculation. ${ }^{3}$ The experimental wavelengths of the $3 d \rightarrow 2 p$ transitions were determined to be slightly longer, and those of the $3 p \rightarrow 2 s$ transitions considerably longer than the predicted values. ${ }^{3}$ Similar discrepancies between experimental and theoretical wavelengths of the $3 p \rightarrow 2 s$ transitions were inferred from cobservations of the $x$-ray transitions in neonlike bismuth in beam-fojl experiments. ${ }^{4}$ The authors speculated that this discrepancy may be due to inadequacies in the calculation of quantum electrodynamical corrections ${ }_{2}$ in particular of the seifenergy: However, the experimental uncertainties of about $6 \mathrm{eV}$ were too large to obtain a definite result. The small amount of high-resolution data obtained 
to date has so far been insufficient to perform a detailed comparison of theory and experiment as a function of atomic number $Z$.

In this paper we axtend the high-resolution measurements of the $3 \rightarrow$ 2 transitions in neonlike silver $(Z-47)$ made previously to the rare earth elements. In particular, we report on measurements of the $\mathbf{i n}=1$ electric dipole, electric quadrupole, and magnetic quadrupole transitions of neonlike xenon $(Z=54)$, lanthanum $(Z=57)$, neodymium $(Z-60)$, and enropium $(Z=63)$, which fall into the $x$-ray region between $2.00 \quad 2.19$ and $2.293 .00 \mathrm{~A}$. The spect ra wercebsersed on Pl'T frum discharges with high celectron ternperatures of up to fi.j kel using a high-resulution Bragg-crestal spectrometer. The uncertainty in the wavelength measurements is :0.1 m.t for most transitions and corresponds to a relative error of $\Delta \lambda / \lambda \approx 1: 200000$.

The data presented in this paper have allowed us to make detailect comparisons between the experimental results and thenretical values which have been obtained from a multiconfigurational Dirac-Fock (AIC'DF) code develuped by Grant and co-workers, 5,6 and which include QED corrections. Although the agreement is generally excellent, small, yet significant differences have been found, which, as in the case of silver, ${ }^{3}$ depend on the type of transition. The magnitude of the differences ranges from about +2.2 eV for transitions of the type $3 p, 3 s-2 p$ to as much as $-2.8 \mathrm{el}$ for transitions of the type $3 d, 3 \mathrm{p}-2 \mathrm{~s}$. In order to understand these discrepancies, we have also made a simple estimate of the residual electron correlation energy arising from electron forsund state correlations and from (super) Coster-Kronig type fluctuations. We find that including the estimate for the residual electron correlation energy in the theoretical transitjun energies reduces the differences between theortical and experimental wavelengths for many transitions. However, the residual electron correlation energy cannot account for all differences. and considerable discrepancies remain for sume types of transitions.

\section{II. - Experimental Arrangement}

The $\mathrm{n}=3$ to $\mathrm{n}=2$ transitions in $\mathrm{Xe}^{4++}, \mathrm{La}^{47-} . \mathrm{Nd}^{50+}$, and $\mathrm{Eu}^{53-}$ were measured using the PLT high-resolution Bragg-crystal spectrometer in Johann 
geometry. ${ }^{7}$ The spectrometer employs a 11 -in $\times 3 \frac{3}{4}$-in $\times 0.06$-in silicon crystal cut to the 220 plane with a $2 \mathrm{~d}_{\infty}$-spacing of $3.8100 \mathrm{~A}$ and bent to a radius of curvature of $365 \mathrm{~cm}$. Misst measurements were perfurmed with the illurumated length of the crystal varying between $2.5 \mathrm{~cm}$ and $10 \mathrm{~cm}$. In the region below $2.19 \mathrm{~A}$ an illuminated length of about $18 \mathrm{~cm}$ was used, in order to maintain an adequate count rate during the measurements of europium. The detector is oriented perpendicular to the line consecting the crystal and the center of the detector, and not tangent to the Rowland circle, as described in Refs. 3 and 7 . As a result, the best focis is achieved in the center of the detector. and the resulution decreases toward the edges. In the wavelength range of interest. $2.00-3.00 A$, the resolution of the centra] part of the spectrum varied from $\lambda / \Delta \lambda \approx 1200$ to $\lambda / \Delta \lambda \approx 8000$. For comparison, the Doppler-broadened line width of xenon corresponded to $\lambda / \Delta \lambda \approx 5000$ at ion temperatures of 1 kel which were typical for the plasma conditions. Six settings were necessary to span the wavelength regions $2.00-2.19$ and $2.29-3.00 \mathrm{~A}$. No measurcments were taken in the region between 2.19 and $2.29 \dot{A}$ due to insufficient machine tirne.

The minimum central electrun temperature necessary to observe $3 \rightarrow 2$ transitions of a given neonlike ion with our instrument on PLT is shown in Fig. 1. The maximum central electron temperature achieved in PLT was approximately $6.5 \mathrm{kel}$ as determined by Thomson scattering. This temperatuse enabled us to observe the transitions between the $\left(2 p_{3 / 2}^{5} 3 s_{1 / 2}\right)_{J=1,2}$ upper states and the grrund state in $E u^{53+}$, although the signal was faint. The lineaveraged electron density in these discharges was $1.0 \times 10^{13} \mathrm{~cm}^{-3}$. The high electron temperatures were obtained with a modest amount of lower-hybrid, radio-frequency heating power $P_{\mathrm{LH}} \approx 650 \mathrm{~kW}$ using a sjde-launching, 16-grill waveguide. 8,9

At each electron temperature shown in Fig. 1 a certain fractional abundance of the corresponding neonlike ions is reached in the centes of the plasma. For instance, aceording to coronal equilibrium values of Breton el al., ${ }^{10}$ the electron temperature of $3.8 \mathrm{keV}$ corresponds to a fractional abundance of about $8 \%$ of xenon in the neonlike state, $\mathrm{Xe}^{44+}$. Similar neonlike ion fractions are predicted by coronal equilibrium calculations for silver, neodymium, and eu- 
ropium. Corsnal equilibrium calculations, however, overestimate the actual abundance in a tokamak plasma. A more realistic equilibrium calculation which includes plasma transport and charge-exchange recombination with neutral hydrogen predicts lower fractions of neonlike ions in PLT plasmas. ${ }^{11}$

Lanthanum, neodymium, and europium were injected into PLT plasmas via laser blow-off. ${ }^{12}$ Xenon was puffed into the plasma using a fast gas valve. In addition, argon and scandium have been introduced into the plastna in or. der to use the resulting hydrengenlike resoriance lines as wavelength references. Furtherumere, titanium, chrorrium, rnanganese. and a small amount of vanadium were indigenous to the plasma, and the hydrugen- and helinmlike spectra of these elements have also been recurded.

\section{Experimental Results}

An overview of the spectral range investigated is given in Fig. 2 which shows the location of the main $\Delta n-1$ neonlike lines as well as the location of the various hydrogen- and heliumlike spectra which were observed. We have normalized our measurements to the theoretical values for the hydrogenic transitiens given in Refs. 13,14, and 15, since these wavelengths can be ralculated with the highest accuracy. ${ }^{13-16}$ In doing so we find that the measured wavelengths of the heliumlike resonance lines $1 s n p^{1} P_{1} \rightarrow 1 s^{2}{ }^{1} S_{0}$ of scandium, titanium, vanadium, and chromium are consistently between 0.1 and $0.2 \mathrm{~mA}$ shorter than predicted by Vainshtein and Safronova. ${ }^{17} A$ similar discrepancy between measured and calculated values for the heliumlike resonance lines had been reported earlier ${ }^{3}$ and may indicate that the theoretical wavelengths computed by Vainshtein and Safromovale are somewhat tore long.

The experimental values of the wavelengths of the $3 s, 3 p, 3 d \rightarrow 2 p$ and $3 d, 3 p-2 s$ transitions are listed in Table 1. They have been determined with respect $t$ s the theoretical wavelength values of the hydrogenic lines given in Table II. The procedures used to identify the neonlike transitions and to determine their respective wavelengths are similar to those described in Ref. 3 for the measurement of $\mathrm{Ag}^{37+}$. The error in the wavelengths of the strung neunlike lines is predominantly determined by the dispersion of the spectrometer, as 
discussed in Ref. 3. The error of weak lines is larger due to larger statistical errors at low count rates. A few transitions have been observed in different settings of the spectrometer. The wavelengths obtained with different settings were reproducible to within $0.1 \mathrm{~mA}$.

Typical spectral data are shown in Figs. 3 and 4 for the case of neodymium. The spectrum in Fig. 3 contains transitions of the type $3 s_{1 / 2} \rightarrow 2 p_{3 / 2}$. The neonlike doublet $\left(2 p_{3 / 2}^{5} 3 s_{1 / 2}\right)_{J=1,2} \rightarrow 2 p^{6}$, denoted $3 G$ and $M / 2$, is readily identifiable. In addition, an array of sodium- magnesium- and possibly aluminumlike satellics can be sern on the long-wavelength side of these lines. The ratio of the satellite line intensity to the intensity of the nemmlike lines in this case is comsiderably larger than the ratio observed previously jn the spectrum of silver. ${ }^{3}$ and may indicate a greater abundance of ions in the hower charge states. The spectrum of the electric dipule transition $3 s_{1 / 2} \rightarrow 2 p_{1 / 2}$, labelled $3 \mathrm{~F}$, and of the electric dipole transition $3 d_{5 / 2} \rightarrow 2 p_{3 / 2}$, labelled $3 D$, is shown in Fig. 4. Again strong satellites due to the corresponding transitions in jons in lower ionization states are seen in the spectrum. Since the detector is not tangent to the Rowland circle, but instead is oriented perpendicular to the line connecting the crystal and the center of the detector, the spectral regions observed with the edges of the detertor have lower resolution than those observed with the the central part of the detector. This effect is especially strong in Fig. 4, where the width of line $3 D$ is inuch larger than the width of line $3 F$.

Subtraction of background spectra, as described earlier in Ref. 3, was reguired in only a few cases. The most notable case is due to a coincidence of line $3 G$ in lanthanum with the resonance transition $1 s 2 p{ }^{1} P_{1} \rightarrow 1 s^{2}{ }^{1} S_{0}$ in $\mathrm{Ti}^{20+}$. As a result, the uncertainty of the measured wavelength of this line is larger than that of most other electric dipole lines.

All but one of the strong electric dipole transitions in neonlike xenon have been measured previously by Conturie et al. from laser-irradiated, impluding mictoballoons, ${ }^{18}$ and several of the strong electric dipole transitions in lanthanum and neodyminm have been measured by Aglitskii et al. in vacuum spark discharges. ${ }^{19}$ The results of these measurements are listed in Table I for comparison. In all cases wur values disagree with these prior measurements by several milliangstroms. This disagreement is larger than the errors quoted in 
Refs. 18 and 19. Part of the disagreement could be due to the fact that theses authors used different transitions and correspondingly different theoretical wavelength values for the calibration of their wavelength measurements. The disagreement may also reflect a possible contamination of the neonlike lines by transjtions in lower charge states as a result of the high densjty and transient nature of laser-produced or spark plasmas.

We have observed two electric quadrupole (E2) transitions of the type $3 d_{5 / 2} \rightarrow 2 s_{1 / 2}$, labelled $E 2 S$. Identification of this type of transition has been reported recently by Gauthier et al. in laser-produced plasmas for strontium, molybdenum, rhodium, and silver. ${ }^{20}$ Further, we have observed $E 2$ transitions of the type $3 p \rightarrow 2 p$. The longest-wavelength $E 2$ line, denoted $E 2 L$ ("lower"), is relatively intense and thus can easily be identified in the spectrum. The shorter-wavelength $E 2$ lines, denoted $E 2 M$ ("middle") and $E 2 U$ ("upper"), are the weakest features observed in the present spectra. Both have been identified in the case of xenon; only one of the two has been identified in lanthanum. The shortest wavelength $E 2$ line in xenon, line $E 2 U$, partially blends with a line which may be due to a transition in a lower charge state, such as aluminum- or siliconlike xenon. Consequently, the value listed for this line in Table I is less certain than those of the other electric quadrupole lines in xenon. The elect.jic quadrupole lines of neodymium which fall into the wavelength region monitored in the present experiment coincide with transitions in the $K \alpha$-spectra of heljumlike chromium and manganese. The E2 transitions in neodymium could not be identified even if backgrourd subtraction techniques were used.

Together with the electric dipole transitions of the type $3 s \rightarrow 2 p$ the electric quadrupole lines can be used to determine the energies of $\Delta n=0$ transitions within the $n=3$ shell. These transitions, in particular the transitions $\left(2 p_{1 / 2}^{5} 3 p_{3 / 2}\right)_{J=2} \rightarrow\left(2 p_{1 / 2}^{5} 3 s_{1 / 2}\right)_{J=1}$ and $\left(2 p_{3 / 2}^{5} 3 p_{3 / 2}\right)_{J=2} \rightarrow\left(2 p_{3 / 2}^{5} 3 s_{1 / 2}\right)_{J=1}$, are of interest in collisionally pumped soft $x$-ray laser schemes. ${ }^{21,22}$ Several of the $3 \rightarrow 3$ intrashell transitions are listed in Table III. A direct measurement of the $3 \rightarrow 3$ transitions is very difficult due to the presence of many lines of nearly identical wavelength which have much higher intensity and which result from $\Delta n=0$ transitions in sodium-, magnesium-, and aluminumlike charge states. 
The values in Table III indicate that the lasing wavelength in a collisionally pumped laser could be reduced to about $58.3 \AA$, if gain were achieved in a lanthanum target. compared to approximately $100 \mathrm{~A}$ in silver, ${ }^{3}$ and $200 \mathrm{~A}$ in selenium. ${ }^{21}$

In the case of xenon we can compare our $\Delta \mathrm{n}=0$ results to those obtained by Dietrich et al. in beam-foil measurements. ${ }^{23}$ Table III shows that our values differ from those in Ref. 23 by amounts which are larger than quoted errors for the two $\Delta n=0$ transitions of the type $3 d \ldots 3 p$. Our values agree with those in Kee. 23 for the remaining three transitions of the type $3 p \rightarrow 3 s$.

Finally: we have also identified one $n=4 t o n=2$ transition in neonlike xenon. which is listed in Table $I$ and is denoted by $+D$. This transition is the $\$ n-2$ analogiee of transition $3 \mathrm{D}$.

\section{Theoretical Results and Comparison with Exper- iment}

The energy levels of neonlike silver, xenon, lanthanum, neodymium, and europium have been calculated using the multironfigurational Dirac-Fock code develuped by Grant and co-workers. ${ }^{5,6}$ The code offers several different choices of calculations. notably an optinal level (OL.) calculation and an extended average level (EAL) calculation. In the OL calculation the basis state wavefunctions are optimized for a particular energy level; in the EAL calculation the wave functions are sbtained by minimizing the average energy of all levels weighted by their respective statistical weights. The code takes into account the interaction betueen any two atomic electrons due to the exchange of a transwerse photon through the use of the frequency-dependent Breit operatorr. ${ }^{24}$ Further, it explicitly calculates corrections arising Irom QED effects. ${ }^{6}$ In particular, the vacuum polarization is evaluated in second order according to a prescription given by Fullerton and Rinker. ${ }^{25}$ The self-energy correction is calrulated based on an effective charge approach. ${ }^{6}$ This approach determines an effective nuclear charge for each orbital and interpolates among the hydrogenic self-energies tabulated by Mohr for the $1 s_{1 / 2}, 2 s_{1 / 2}, 2 p_{1 / 2}$, and $2 p_{3 / 2}$ levels. ${ }^{26-28}$ For levels with principal quantrom number $n \geq 3$ the $n^{-3}$ scaling 
rule $^{29}$ is used to estimate the self-energies. ${ }^{6}$ In order to get the self-energy correction to a given transition energy. the sum of the self-energies of ever: electron in both the initial and final states is calculated and then subtracted. As a result, the procedure takes into account energy shifts due to relaxation effects. Effects due to the finite nuclear size are taken intw account by employing the Fermi model for the nuclear charge distribution. ${ }^{30}$

The results of the MCDF calculations are listed in Table IV. All energies except thuse of the $3 d-2 p$ transitions labelled $3 C^{\prime}$ and $3 D$ were obtailled using the EAL procedure and including all 36 singly excited states with a holk in the $n=2$ shell and a single electron in the $n=3$ shell. The transition energy of line $4 D$ in xenon was calculated in similar fashion by applying the EAL procedure to the $n=4$ spectroscopir complex. For comparison we have calculated the transition energies of lanthanum using the OL approach. The resulting energies differ from the values obtained in the EAL calculation by less than $0.2 \mathrm{eV}$. The only exceptions are transitions $3 C$ and $3 D$. The theoretical energies obtained from the $\mathrm{OL}$ calculations are $0.7 \mathrm{eV}$ lower in the case of transition $3 C$ and $0.5 \mathrm{eV}$ lower in the case of transition $3 D$ than the values whained from the EAL calculation. Comsequently, we have recalculated the $3 d-2 p$ transition energies for all elements in the $\mathrm{OL}$ approach, since we deem the $O L$ calculations to be more arcurate. The resulting values are listed in Table IV. The relativistic Conlumb energies, $\mathrm{E}_{\text {Coulomb }}$, the Breit interaction energies, $\mathrm{E}_{\text {Breit }}$, and the QED corrections, which make up the total transition energy, $E_{\text {Tor AL, }}$ are listed separately in Table IV. The calculations show that the QED corrections are a significant part of $\mathrm{E}_{\text {TOTAL }}$. The QEI) corrections are largest for the transitions involving a $2 s$-hole state, namely for the transitions labelled $3 A, 3 B$, and E2S. In the case of lanthanum the calculated QED corrections of these levels is over $6 \mathrm{eV}$, which is ahout one part in one thousand. The predicted size of the radiative corrections of the $3 s$ levels is considerably smaller. It ranges between $0.7 \mathrm{eV}$ in silver to $1.8 \mathrm{eV}$ in europium for the transitions $3 G$ and $M / 2$, and is about $30 \%$ larger for transition $3 F$.

In the last column of Table IV, a comparison is made between the theoretical energies and the experimental values. Here $\triangle E$ is defined as the difference 
between the experimental minus the theoretical energy, i.e.,

$$
\Delta \mathrm{E} \equiv \mathrm{E}_{\exp }-\mathrm{E}_{T O T A L}
$$

The uncertainty in $\Delta \mathrm{E}$ is listed in the table and reflects solely the uncertainty in the experimental values. For this purpose the measured wavelengths given in Table I were converted to energies using the conversjon constant hc/e = $12398.54 \mathrm{eV} \AA{ }^{31}$ We have included the values of $\Delta \mathrm{E}$ for silver which we had measured earlier. ${ }^{3}$ For consistency with the data for the higher- $Z$ elements, the experimental energies of the silver transitions were re-referenced to hydrogenic calibration lines instead of the helumlike reference lines used in Rel. 3 . The rereferencing has had the effect of increasing the value of $\mathrm{E}_{\exp }$ by approximately $0.3 \mathrm{eV}$.

The largest deviation of the theoretical energies from the experimental values is less than $2.8 \mathrm{eV}$, or 0.5 parts per thousand. A close examination of the differences shows that the differences are not random. Instead, $\Delta \mathrm{E}$ exhibits systematic variations which depend on the type of transition, and which to a lesser extent also depend on $Z$. These variations can be seen in Fig. 5, where the values of $د \mathrm{E}$ are plotted separately for different types of transitions as a function of $Z$. The figure shows that $\triangle \mathrm{E}$ is generally positive for transitions into a $2 p$-racancy state, and negative for transitions into a $2 s-$ vacancy state. The values of $\Delta \mathrm{E}$ of the $3 s \rightarrow 2 p$ transitions, labelled $3 G$ and $M 2$, are plotted in Fig. 5(a). The values vary between $1.2 \mathrm{eV}$ and $1.8 \mathrm{eV}$. Figure 5(a) also shows the ralues of $\Delta \mathrm{E}$ of the $3 d, 3 p \rightarrow 2 s$ transitions. In this case the average values decrease from about $-1.4 \mathrm{eV}$ in silver to $-2.5 \mathrm{eV}$ in lanthanum. The values of $\Delta \mathrm{E}$ for the $3 s \rightarrow 2 p$ transitions, labelled $3 F$, are shown in Fig. 5(b) and nearly equal those of $3 G$ and $M 2$ except for the point at $\mathrm{Z}=60$. The values of $\Delta \mathrm{E}$ of the $3 d \rightarrow 2 p$ transitions are plotted in Fig. $5(c)$. For transitions $3 D, \Delta \mathrm{E}$ equals about $+0.6 \mathrm{eV}$ except in the case of xenon where $\triangle E$ vanishes. For the transitions $3 C$, which involve states of different angular momentum, $\Delta \mathrm{E}$ is slightly above $+1 \mathrm{eV}$. In Fig. 5(d) we plot $\Delta \mathrm{E}$ for transitions of the type $3 p \rightarrow 2 p$. The magnitude of $\Delta \mathrm{E}$ is found to be about 0.5 $\mathrm{eV}$ larger for the $2 p_{J=1 / 2}^{5}$-vacancy states than for the $2 p_{J=3 / 2}^{5}$-vacancy states, although the values of $\Delta \mathrm{E}$ for both types of transitionis are comparable to the 
values found for the $3 s \rightarrow 2 p$ iransitions. The value of $\triangle \mathrm{E}$ for transition $4 D$ is also comparable to those of the $3 s \rightarrow 2 p$ transitions.

The EAL scheme used to calculate the values in Table IV includes configuration interaction from the same complex only. The same holds true for the $O L$ scheme used to calculate the energies of the transitions $3 C$ and $3 D$. Consequently, we do not expect the theoretical transition energies given in Table IV to agree exactly with the ex irimental values. Instead we expect $\Delta \mathrm{E} \approx$ $\mathrm{E}_{C}$, where $\mathrm{E}_{C}$ is the residual electron correlation energy. In the following we estimate the magnitude of $\mathrm{E}_{C}$ and compare its value to $د \mathrm{E}$.

Ideally, the correlation contribution to the transition energy should be determined by calculating the total correlation energies of the ground state and each excited state and by taking the difference. However, since such a procedure is extremely involved, the simpler approach of Chen et al. is used. ${ }^{2,32}$ Here the correlation energies of the passive electrons from the ground and excited state are assumed to cancel. The two dominant correlation corrections which remain after the cancellation are the ground state correlation correction, $\mathrm{E}_{g s}$, and, in the case of the $2 s$-hole states, the energy shift, $\mathrm{E}_{C K}$, due to CosterKronig and super-Coster-Kronig fluctuations. Hence, $\mathrm{E}_{C} \approx \mathrm{E}_{g}$, for the $2 p$-hole states; and $\mathrm{E}_{C} \approx \mathrm{E}_{g}+\mathrm{E}_{C K}$ for the 2s-hole states.

The ground state correlation energy arises because pairs are broken in the excitation. Since all pair energies are negative and since there are more pairs in the ground state than in the excited state, this effect increases the transition energies. As a result $E_{g s}$ is pcsicive. Furthermore, we make use of the findings by Öksüz and Sinanoglu ${ }^{33,34}$ that all-external pair correlation energies are approximately constant as a function of $\mathrm{Z}$ and as a function of the number of electrons in a given element. This allows us to estimate the residual pair correlation energy based on a nonrelativistic calculation of the pair energies for neutral zinc performed by Jankowski et al. ${ }^{35}$ As a result we obtain $E_{g,}=1.7 \mathrm{eV}$ for transitions involving a $2 p$-vacancy state, and $E_{g s}=$ $1.0 \mathrm{eV}$ for transitions involving a $2 s$-vacancy state.

The energies of the transitions $3 d, 3 p \rightarrow 2 s$ are affected not only by ground state correlations but also by (super) Coster-Kronig fluctuations of the hole state. $^{2,32,36,37}$ This dynamic relaxation process in which the core hole fluctu- 
ates to intermediate levels of the Coster-Kronig or super-Coster-Kronig type, reduces the transition energies. The effect can be accounted for by allowing for configuration interactions with the states $\left(2 s^{2} 2 p^{4} 3 l 3 d\right)_{J=1,2}$ in the MCDF calculation and by using the OL method. The results of these calculations are given in Table $V$. The energy shift $\mathbf{E}_{C K}$ due to the (super) Custer-Kronig type fluctuations is obtained by subtracting $\mathrm{E}_{\text {TOTAL }}$ given in Table IV from

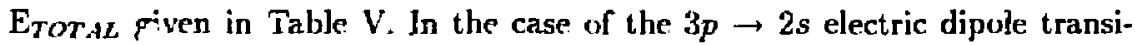
tions the (super) Coster-Kronig fluctuations reduce the transition energies by $1.9 \mathrm{eV}$. The reduction is not as large for the energies of the $3 d \rightarrow 2 s$ electric quadrupule transitions. In this case the reduction is $0.9 \mathrm{eV}$.

The values of the residual electron correlation energy can now be obtained by ardding the values for $\mathrm{E}_{g}$, and $\mathrm{E}_{C K}$. As a result we obtain $\mathrm{E}_{C} \approx+1.7 \mathrm{el}$ for all transitions into a $2 p$-vacancy state, $\mathrm{E}_{C} \approx-0.9 \mathrm{eV}$ in the case of the electric dipole transitions $3 p \rightarrow 2 s$, and $\mathrm{E}_{C} \approx+0.1 \mathrm{eV}$ in the case for the electric quadrupole transitions $3 d \rightarrow 2 s$.

Comparing the values of $E_{C}$ to those of $\Delta \mathrm{E}$ we find that for many, but not all transitions the agreement of the theoretical energies with the experimental data is improved. $E_{C}$ and $\Delta E$ are of comparable size, in particular for the transitions $M 2,3 G, 3 F, 4 D$, and $E 2 U$. Thus, the addition of $\mathrm{E}_{C}$ to $\mathrm{E}_{T O T A L}$ improves the agreement between theory and experiment in this case. The opposite is true for transitions $3 D$ where the inclusion of $E_{C}$ in the theoretical values worsens the agreenent between theory and data. Addition of $\mathrm{E}_{C}$ to $\mathrm{E}_{\text {TotAL }}$ reduces the discrepancy between theory and data for the transitions $3 p \rightarrow 2 s$. The remaining discrepancies for transition 3.4 range from as little as $-0.74 \mathrm{eV}$ in silver to $-1.19 \mathrm{eV}$ in xenon, and $-1.36 \mathrm{eV}$ in lanthanum. No improvement is achieved for the $3 d \rightarrow 2 s$ electric quadrupole transitions. The disagreement of the theoretical values with the data remains largest for these transitiens and ranges from $-2.55 \mathrm{eV}$ in xenon to $-2.88 \mathrm{eV}$ in lanthanum.

Part of the discrepancy between the theoretical and experimental values may be due to inadequacies in treating the electron pair correlation energies. Our simple estimate is based on the nonrelativistic calculation for neutral zinc, $^{35}$ because no suitable relativistic calculation exists. A fully relativistic calculation of the correlation energies for high- $Z$ neonlike systems could im- 
prove our estimate considerably.

A further cause for the discrepancy between theoretical and experimental values may be an inadequate treatment of the self-energy contribution to the transition energy. Table IV shows that the radiative corrections are largest for the $2 s$-vacancy states. Consequently, an error in the value of the self-energy will affect these levels the most, and, conversely, if there are problems with the radiative corrections, they will most likely be found in these levels. The values of the self-energy listed in Table IV are obtained from hydrogenic values which are adjusted for screening. ${ }^{6}$ On the other hand, the use of hydrogenic se]f-energies ${ }^{28}$ lewwers the theoretical energies of the $3 d, 3 p \rightarrow 2 s$ transitions by approsimately $1.1 \mathrm{eV}, 1.7 \mathrm{eV}$, and $2.0 \mathrm{eV}$ in the case of silver, xenon, and lantharnum, respectively and improves the agreement with the data. The improved agreement, however, may be completely fortuitous. There is no a priori reason to believe that the use of hydrogenic self-energies (bare or screened) is valid in a regime where the orbitals are very much nonhydrogenic, as in the case of ten-electron, neonlike systems.

\section{Summary}

The emphasis of this paper has been to present a coherent set of wavelength data which can be used for comparison with thenretical results. In particular, we have reported on wavelength measurements of $\mathrm{x}$-ray transitions in $\mathrm{Xe}^{44+}$, $\mathrm{La}^{47+}, \mathrm{Nd}^{50+}$, and $\mathrm{Eu}^{53+}$ which were observed in the wavelength region 2.002.19 and $2.29-3.00 \hat{A}$. The measurements include the strong electric dipole transitions $3 d \rightarrow 2 p, 3 s \rightarrow 2 p$, and $3 p \rightarrow 2 s$ as well as the weaker electric quadrupole transitions $3 p-2 p$ and $3 d-2 s$. Further, the strong magnetic quadrupole transition $\left(2 p_{3 / 2}^{5} 3 s_{1 / 2}\right)_{J=2} \rightarrow$ ground state has been observed for each element. We have also identified one $\Delta n=2$ transition of the type $4 d \rightarrow 2 p$ in neonlike xenon. The wavelength of each transition was determined with high accuracy ( $\pm 0.1 \mathrm{~mA}$ for most lines) with the help of a multitude of reference spectra from hydrogenlike ions.

Together with the wavelengths of neonlike silver measured arlier $^{3}$ the data have been used for comparison with multiconfigurational relativistic atomic 
structure calculations. The comparisons reveal differences the magnitudes of which depend on the particular type of transition and which vary smoothly with $Z$. For all transitions to $2 p$-vacancy states except transition $3 b$ the magnitude ranges between +0.9 and $+2.2 \mathrm{eV}$. For transition $3 D$ the magnitude of the differences ranges only between zero and $+0.6 \mathrm{eV}$. The residual electron correlation energy for the transitions into a $2 p$-vacancy state has been estimated to equal $E_{C} \approx+1.7 \mathrm{eV}$ so that $\mathrm{E}_{C}$ is comparable in size to the magnitude of most differences. Consequently. adding $\mathrm{E}_{C}$ to the calculated energies improwes the agreement of the theoretical values with the data for many transitions. csprecially in the case of the $3 s \rightarrow 2 p$ transitions. For the transitions into a $2 s$-vacancy state the experimental energies are significantly less than those predicted Iy the MCDF calculations. Inclusion of electron correlations due to ground state correlations and (super) Coster-Kronig type fluctuations in the theoretical transition energies reduces the discrepancy between experimental and theoretical energies in the case of the $3 p \rightarrow 2 s$ transitions. The magnitude of the remaining discrepancies for transition 3.4 ranges from $-0.76 \mathrm{eV}$ in silver to $-1.36 \mathrm{eV}$ in lanthanum. Inclusion of residual electron correlations in the MC.DF values does not diminish the discrepancy of the $3 d-2 s$ electric quadrupole transitions. Here the discrepancies are $-2.55 \mathrm{eV}$ and $-2.88 \mathrm{eV}$ in xenon and lanthanum, respertively. The discrepancies found after accounting for the additional electron correlations indicate strongly that further work is naeded to resolve the differences.

The measurements presented in this paper were obtained in plasmas with electron temperatures in the range $4-6.5 \mathrm{keV}$. Based on the trends shown in Fig. 1 we can estimate that a peak electron temperature near $10 \mathrm{keV}$ is needed to observe $x$-ray transitions in neonlike ions with atomic number $Z \approx 70$. Temperatures in this range may be achieved in tokamaks with additional electron heating power or with electron heating as a by-product of ion heating in fusion devices. High-resolution measurements of neonlike transitions in such very high-electron temperature plasmas are bound to vield new insights into our understanding of the structure of high- $Z$. multi-electron systems. 


\section{Acknowledgments}

We are grateful for the support and encouragement provided by M. Eckart, H. Furth, A. Torr, and L. Wood. We would like to thank K. Vlann, J. Anastasio, H. Anderson, and J. Gething, as well as J. Gorman, J. Lehner, and M. Saracino for their technical support. This work was supported by Lawrence Livermore National Laboratory under subcontracts No. SANL-622-033 and 8-668-705, and by the U. S. Department of Energy under contracts No. DEACO2-76-CHO-3073 and $W$-7405-ENC-48. One of the anthors (PB) was supported by the Fannie and Juhn Hertz Foundation. 


\section{References}

'J. F. Seely, J. O. Ekberg, C. M. Brown, U. Feldman, W. E. Behring, J. Reader, and M. C. Richardson, Phys. Rev. Lett. 57, 2924 (1986).

${ }^{2}$ M. H. Chen, Phys. Rev. A 36, 665 (1987).

${ }^{3}$ P. Beiersdorfer, M. Bitter, S. von Goeler, S. Cohen, K. W. Hill, J. Timberlake, R. S. Walling, M. H. Chen, P. L. Hagelstein, and J. H. Scofield, Phys. Rev: A 34, 1297 (1986).

${ }^{4}$ D. D. Dietrich, G. A. Chandler, P. O. Egan, K. P. Ziock, P. H. Mokler, S. Reusch, and D. H. H. Hoffmann, Nucl. Instr. Meth. B24/25, 301 (1987).

${ }^{5}$ I. P. Grant, B. J. McKenzie, P. H. Norrington, D. F. Mayers, and N. C. Pyper, Comput. Phys. Commun. 21, 207 (1980).

${ }^{6}$ B. J. McKenzie, I. P. Grant, and P. H. Norrington, Comput. Phys. Commun. 21, 233 (1980).

${ }^{7}$ K. W. Hill, S. von Goeler, M. Bitter, L. Campbell, B D. Cowan, B. Fraenkel, A. Greenberger, R. Horton, J. Hovey, W. Roney, N. R. Sauthoff, and W. Stodiek, Phỵs, Rev. A 19, 1770 (1979).

8J. E. Stevens, R. Beil, S. Bernabei, A. Cavallo, T. K. Chu, P. Colestock, W. Hooke, J. Hosea, F. Jobes, T. Luce, E. Mazzucato, R. Motley, R. Pinsker, S. von Goeler, and J. R. Wilson, Nucl. Fus. (to be published).

${ }^{9}$ R. E. Bell, S. Bernabei, A. Cavallo, T. K. Chu, T. Luce, R. Motley, M. Ono, J. Stevens, and S. von Goeler, Princeton Plasma Physics Laboratory Report No. PPPL-2452, 1987.

${ }^{10} \mathrm{C}$. Breton, C. De Michelis, M. Finkenthal, and M. Mattioli, Fontenay-auxRoses Laboratory Report No. EUR-CEA-FC-948, 1978.

${ }^{11}$ R. A. Hulse, Nucl. Tech. Fus. 3, 259 (1983). 
${ }^{12}$ E. S. Marmaz, J. L. Cecchi, and S. A. Cohen, Rev. Sci. Instrum. 46, 1149 (1975).

${ }^{13}$ J. D. Garcia and J. E. Mack, J. Opt. Soc. Am. 55, 654 (1965).

${ }^{14}$ G. W. Erickson, J. Phys. Chem. Ref. Data 6, 831 (1977).

${ }^{15}$ W. R. Johnson and G. Sof, At. Data Nucl. Data Tables 33, 405 (1985).

${ }^{16}$ P. Mohr, At. Data Nucl. Data Tables 29, 453 (1983).

${ }^{17}$ L. A. Vainshtein and U. I. Safronova, Phys. Scripta 31, 519 (1985).

${ }^{18}$ Y. Conturie, B. Yaakobi, U. Feldman, G. A. Doschek, R. D. Cowan, J. Opt. Soc. Am. 71, 1309 (1981).

${ }^{19}$ E. V. Aglitskii, P. S. Antsiferov, A. M. Panin, and S. A. Ulitin, Opt. Spectrosc. (LSSR) 60, 122 (1986).

${ }^{20}$ J.-C.Gauthier, J.-P.Geindre, P. Monjer, E. Luc-koenig, and J. Wyar', J. Phys. B: At. Mol. Phys. 19, L385 (1986).

${ }^{21}$ D. L. Matthews, P. L. Hagelstein, M. D. Rosen, M. J. Eckart, N. M. Ceglio, A. U. Hazi, H. Medecki, B. J. Macgowan, J. E. Trebes, B. L. Whitten, E. M. Campbell, C. W. Hatcher, A. M. Hawryluk, R. L. Kauffman, L. D. Pleasance, G. Rambach, J. H. Scofield, G. Stone, and T. A. Weaver, Phys. Rev. Lett. 54, 110 (1985).

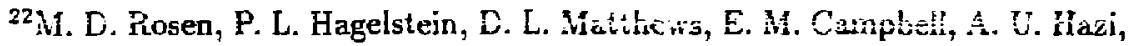
B. L. Whitten, B. MacGowan, R. E. Turner, R. W. Lee, G. Charatis, G. E. Busch, C. L. Shepard, and P. D. Rockett, Phys. Rev. Lett. 54, 106 (1985).

${ }^{23}$ D. D. Dietrich, G. A. Chandler, R. J. Fortner, C. J. Hailey, and R. E. Stewart, Phys. Rev. Lett. 54, 1008 (1985).

${ }^{24}$ I. P. Grant and B. J. McKenzie, J. Phys. B 13, 2671 (1980).

${ }^{25}$ L. W. Fullerton and G. A. Rinker, Jr., Phys. Rev. A 13, 1283 (1976). 
${ }^{26}$ P. J. Mohr, Ann. Phys. 88, 52 (1974).

${ }^{27}$ P. J. Mohr, Phys. Rev. Lett. 34, 1050 (1975).

${ }^{28}$ P. J. Mohr, Phys. Rev. A 26, 2338 (1982).

${ }^{29}$ H. A. Bethe, Phys. Rev. 72, 339 (1947).

${ }^{30}$ M. H. Chen, B. Crasemann, M. Aoyagi, K.-N. Huaug, and H. Mark, At. Data Nucl. Data Tables 26, 561 (1981).

${ }^{31}$ Value based on a 1984 revision of the Physical Constants by B. N. Taylor, in X-Ray Data Booklet, edited by D. Vaughan (Center for X-Ray Optics, Lawrence Berkeley Laboratory, University of California, Berkeley, 1986); E. R. Cohen and B. N. Taylor, J. Chern. Ref. Data 2, 663 (1973).

${ }^{32}$ M. H. Chen, B. Crasemann, N. Mårtensson, and B. Johansson, Phys. Rev. A 31, 556 (1985).

${ }^{33} \mathrm{i}$. Öksüz and O. Sinanoğlu, Phys. Rev. 181, 12 (1969).

${ }^{34}$ I. Öksüz and O. Sinanoğlu, Phys. Rev. 181; 54 (1969).

${ }^{35}$ K. Jankowski, P, Malinowski, and M. Polasik, J. Chem. Phỵs. 76, 448 (1982).

${ }^{36} \mathrm{M}$. Ohno and G. Wendin, J. Phys. B 11, 1557 (1978).

${ }^{37}$ M. Ohno and G. Wendin, J. Phys. B 12, 1305 (1979). 


\section{Tables}

TABLE I. Experimental wavelengths of the $\mathrm{x}$-ray transitions observed in $\mathrm{Xe}^{44-}, \mathrm{La}^{47+}$ : $\mathrm{Nd}^{50+}$, and $\mathrm{Eu}^{53+}$. Each wavelength is determined with respect to the wavelength of the hydrogenic reference line listed in the last column. The experimental uncertainties are indicated in parentheses, e.g., 2.1601(1) means $2.4601 \div 0.0001$.

\begin{tabular}{|c|c|c|c|c|c|}
\hline Element & $\begin{array}{l}\text { Upper } \\
\text { Level }\end{array}$ & $\overline{K e y}$ & $\begin{array}{l}\lambda_{\text {exp }}^{a} \\
(\bar{A})\end{array}$ & $\begin{array}{l}\lambda_{\text {exp }} \\
(A)\end{array}$ & $\begin{array}{c}\overline{\text { Reference }} \\
\text { Line }\end{array}$ \\
\hline \multirow[t]{12}{*}{ Tenon } & $\left(2 p_{3 / 2}^{5} 3 s_{1 / 2}\right)_{J=2}$ & $M / 2$ & $2.9449(1)$ & & $\operatorname{Ar} \mathrm{L} y \cdot \delta$ \\
\hline & $\left(2 p_{3 / 2}^{5} 3 s_{1 / 2}\right)_{J=1}$ & 36 & $2.9411(1)$ & $2.940^{b}$ & $\operatorname{Ar} \mathrm{Ly} \quad \delta$ \\
\hline & $\left(2 p_{3 / 2}^{5} 3 p_{1 / 2}\right)_{J-2}$ & $E 2 L$ & $2.8799(1)$ & & Ar Ly $c$ \\
\hline & $\left(2 p_{3 / 2}^{5} 3 p_{3 / 2}\right)_{J=2}$ & $E: M$ & $2.8186(1)$ & & Ar Ly- $\epsilon$ \\
\hline & $\left(2 p_{1 / 2}^{5} 3 s_{1 / 2}\right)_{1-1}$ & $3 F$ & $2.7288(1)$ & $2.7^{\circ} 25^{b}$ & Sr $L y-\alpha_{1}$ \\
\hline & $\left(2 p_{3 / 2}^{5} 3 d_{5 / 2}\right)_{J, I}$ & $3 D$ & $2.7203(1)$ & $2.718^{6}$ & Sr $L y-\alpha_{1}$ \\
\hline & $\left(2 p_{1 / 2}^{5} 3 p_{3 / 2}\right)_{J=2}$ & $E 2 U^{\prime}$ & $2.6221(2.5)$ & & $\Gamma \mathbf{i} L y-\alpha_{1}$ \\
\hline & $\left(2 p_{1 / 2}^{5} 3 d_{3 / 2}\right)_{J=1}$ & $3 C$ & $2.5525(1)$ & $2.549^{6}$ & Ti Ly $-\alpha_{1}$ \\
\hline & $\left(2 s_{1 / 2} 3 p_{1 / 2}\right)_{\lrcorner-1}$ & $3 B$ & $2.5052(1.5)$ & & Ti Ly $-\alpha_{1}$ \\
\hline & $\left(2 s_{1 / 2} 3 p_{3 / 2}\right)_{J=1}$ & $3 A$ & $2.4601(1)$ & & Ti Ly $-\alpha_{1}$ \\
\hline & $\left(2 s_{1 / 2} 3 d_{5 / 2}\right)_{J=2}$ & $E 2 S$ & $2.3941(1)$ & & Sc $L y-\beta_{1}$ \\
\hline & $\left(2 p_{3 / 2}^{5} 4 d_{5 / 2}\right)_{J=1}$ & $4 D$ & $2.0957(1)$ & & CT Ly $-\alpha_{1}$ \\
\hline \multirow[t]{8}{*}{ Lanthanumn } & $\left(2 p_{3 / 2}^{5} 3 s_{1 / 2}\right)_{J=2}$ & $M 2$ & $2.6133(1)$ & & Ti $L y-\alpha_{1}$ \\
\hline & $\left(2 p_{3 / 2}^{5} 3 s_{1 / 2}\right) J=1$ & $3 G$ & $2.6100(2)$ & $2.6142^{c}$ & $T j L y-\alpha_{1}$ \\
\hline & $\left(2 p_{3 / 2}^{5} 3 p_{1 / 2}\right)_{J=2}$ & $E 2 L$ & $2.5580(1)$ & & $\mathrm{Tj} L y-\alpha_{1}$ \\
\hline & $\left(2 p_{2 / 2}^{5} 3 d_{5 / 2}\right)_{J=1}$ & $3 D$ & $2.4139(1)$ & $2.4149^{c}$ & Sc $L_{y}-\beta_{1}$ \\
\hline & $\left(2 p_{1 / 2}^{5} 3 s_{1 / 2}\right)_{J=1}$ & $3 F$ & $2.3965(1)$ & & Sc $L y-\mathcal{B}_{1}$ \\
\hline & $\left(2 p_{1 / 2}^{5} 3 p_{3 / 2}\right)_{J=2}$ & $E 2 U$ & $2.3019(2)$ & & Sc $L y-\beta_{1}$ \\
\hline & $\left(2 s_{1 / 2} 3 p_{3 / 2}\right)_{J=1}$ & 3.4 & $2.167 \perp(1.5)$ & $2.1687^{c}$ & Cr Ly- $-\alpha_{1}$ \\
\hline & $\left(2 s_{1 / 2} 3 d_{5 / 2}\right)_{J=2}$ & $E 2 S$ & $2.1108(1.5)$ & & $\mathrm{Cr} L y-\alpha_{1}$ \\
\hline \multirow[t]{4}{*}{ Neodymium } & $\left(2 p_{3 / 2}^{5} 3 s_{1 / 2}\right)_{J=2}$ & $M I 2$ & $2.3359(1)$ & & Sc $L y-\mathcal{B}_{1}$ \\
\hline & $\left(2 p_{3 / 2}^{5} 3 s_{1 / 2}\right)_{J=1}$ & $3 G$ & $2.3331(1)$ & & Sc $L y-\beta_{1}$ \\
\hline & $\left(2 p_{3 / 2}^{5} 3 d_{5 / 2}\right)_{J=1}$ & $3 D$ & $2.1543(1.5)$ & $2.1573^{c}$ & $\mathrm{C}_{r} \mathrm{~L} y-\alpha_{1}$ \\
\hline & $\left(2 p_{1 / 2}^{5} 3 s_{1 / 2}\right)_{J=1}$ & $3 F$ & $2.1206(1.5)$ & & $\mathrm{C} r \mathrm{~L} y-\alpha_{1}$ \\
\hline \multirow[t]{2}{*}{ Europium } & $\left(2 p_{3 / 2}^{5} 3 s_{1 / 2}\right)_{J=2}$ & $M 2$ & $2.1015(2)$ & & Sc $L y-\beta_{1}$ \\
\hline & $\left(2 p_{3 / 2}^{5} 3 s_{1 / 2}\right)_{J=1}$ & $3 G$ & $2.0990(2)$ & & $\operatorname{CrL} y-\alpha_{1}$ \\
\hline
\end{tabular}

- Present measurement.

bConturie et al., Rer. 18

${ }^{c}$ Aglitskii el al., Ref. 19 
TABLE II. Wavelengths of the hydrogenic transitions used as references in the measurement of the neonlike transitions. $<>$ denotes average.

\begin{tabular}{ccc}
\hline $\begin{array}{l}\text { Reference } \\
\text { Line }\end{array}$ & Transition & $\begin{array}{c}\lambda_{\text {theoru }} \\
(\AA)\end{array}$ \\
\hline Ar $L y-\delta$ & $5 P_{3 / 2} \rightarrow 1 S_{1 / 2}, 5 P_{1 / 2} \rightarrow 1 S_{1 / 2}$ & $<2.91756>^{a}$ \\
Ar $L y-\epsilon$ & $6 P_{3 / 2} \rightarrow 1 S_{1 / 2}, 6 P_{1 / 2} \rightarrow 1 S_{1 / 2}$ & $<2.88095>^{a}$ \\
Sc $L y-\alpha_{1}$ & $2 P_{3 / 2} \rightarrow 1 S_{1 / 2}$ & $2.73602^{b}$ \\
Ti $L y-\alpha_{1}$ & $2 P_{3 / 2} \rightarrow 1 S_{1 / 2}$ & $2.49120^{b}$ \\
Sc $L y-\beta_{1}$ & $3 P_{3 / 2} \rightarrow 1 S_{1 / 2}$ & $2.31066^{\mathrm{c}}$ \\
Cr $L y-\alpha_{1}$ & $2 P_{3 / 2} \rightarrow 1 S_{1 / 2}$ & $2.09014^{b}$ \\
\hline
\end{tabular}

${ }^{\circ}$ Garcia and Mark, Ref. 13

'Johnson and Soff, Ref. 15

'Erickson, Ref. 14

TABLE III. Experimental intrashell intervals in $\mathrm{Xe}^{44+}$ and $\mathrm{La}^{47+}$.

\begin{tabular}{clcc}
\hline \hline Element & \multicolumn{1}{c}{ Transition } & $\begin{array}{c}\text { Energy } \\
(\mathrm{eV})\end{array}$ & $\begin{array}{c}\bar{E}_{\text {nergy }} \\
(\mathrm{eV})\end{array}$ \\
\hline Xenon & $\left(2 p_{3 / 2}^{5} 3 p_{1 / 2}\right)_{J=2} \rightarrow\left(2 p_{3 / 3}^{5} 3 s_{1 / 2}\right)_{J=1}$ & $89.6 \pm 0.4$ & $89.1 \pm 0.5$ \\
& $\left(2 p_{3 / 2}^{5} 3 p_{3 / 2}\right)_{J=2} \rightarrow\left(2 p_{3 / 3}^{5} 3 s_{1 / 2}\right)_{J=1}$ & $183.2 \pm 0.4$ & $182.9 \pm 0.5$ \\
& $\left(2 p_{1 / 2}^{5} 3 p_{3 / 2}\right)_{J=2} \rightarrow\left(2 p_{1 / 2}^{5} 3 s_{1 / 2}\right)_{J=1}$ & $184.9 \pm 0.7$ & $186.5 \pm 1$ \\
& $\left(2 p_{3 / 2}^{5} 3 d_{5 / 2}\right)_{J=3} \rightarrow\left(2 p_{3 / 3}^{5} 3 p_{3 / 2}\right)_{J=2}$ & $159.0 \pm 0.3$ & $157.2 \pm 0.5$ \\
& $\left(2 p_{1 / 2}^{5} 3 d_{3 / 2}\right)_{J=1} \rightarrow\left(2 p_{1 / 2}^{5} 3 p_{3 / 2}\right)_{J=2}$ & $129.0 \pm 0.7$ & $131.3 \pm 1$ \\
& & & \\
Lanthanum & $\left(2 p_{3 / 2}^{5} 3 p_{1 / 2}\right)_{J=2} \rightarrow\left(2 p_{3 / 2}^{5} 3 s_{1 / 2}\right)_{J=1}$ & $96.7 \pm 0.4$ & \\
& $\left(2 p_{1 / 2}^{5} 3 p_{3 / 2}\right)_{J=2} \rightarrow\left(2 p_{1 / 2}^{5} 3 s_{1 / 2}\right)_{J=1}$ & $212.8 \pm 0.4$ \\
\hline
\end{tabular}

${ }^{a}$ Present measurement

${ }^{b}$ Dietrich et al., Ref. 23 
TABLE IV. Comparison between theoretical and experimental energies. The theoretical values were obtained from an extended average level calculation except transitions $3 C$ and $3 D$ which were calculated in the optimum level approach. $E_{\text {Condomb }}$ is the relativistic Coulornb energy, $E_{B r e i t}$ is the transverse Breit correction, $\mathrm{E}_{V^{\prime} P}$ is the vacuum polarization energy, $\mathrm{E}_{S E}$ is the self-energy, and $\mathrm{E}_{T O T A L}$ is the sum of the preceding columns. $\triangle \mathrm{E}$ is defined as the difference between the experimental energies and $E_{T O T A L^{-}}$The experimental values for xenon, lanthanum, neodymium, and europium are from Table I. The experimental values of silver are from Ref. 3. The uncertainties in $\Delta E$ are indicated in parentheses and are solely due to uncertainties in the experimental values; here $1.56(10)$ means $1.56 \pm 0.10$.

\begin{tabular}{|c|c|c|c|c|c|c|c|}
\hline Element & $\bar{K} e y$ & $\begin{array}{c}\mathrm{E}_{\text {Coulomb }} \\
(\mathrm{eV})\end{array}$ & $\begin{array}{c}E_{\text {Breit }} \\
(\mathrm{eV})\end{array}$ & $\begin{array}{l}\mathrm{E}_{V P} \\
(\mathrm{eV})\end{array}$ & $\begin{array}{c}\mathrm{E}_{S E} \\
(\mathrm{eV})\end{array}$ & $\begin{array}{c}\mathrm{E}_{T O T A L} \\
(\mathrm{eV})\end{array}$ & $\begin{array}{c}\Delta \mathrm{E} \\
(\mathrm{eV})\end{array}$ \\
\hline \multirow[t]{10}{*}{ Silver } & $M 2$ & 3083.18 & -4.39 & $-\overline{0.14}$ & $-\overline{0.83}$ & 3079.49 & $+1.56(10)$ \\
\hline & $3 G$ & $308 ?$ & -4.30 & -0.14 & -0.83 & 3084.12 & $+1.43(10)$ \\
\hline & $E 2 L$ & 3161 & - & -0.02 & -0.09 & 315 & $+0.92(10)$ \\
\hline & $E 2 M$ & 32 & - & -0.02 & 0.02 & 320 & $+1.03(10)$ \\
\hline & $3 F$ & 326 & - & 12 & 1.11 & 32 & $+1.25(10)$ \\
\hline & $3 D$ & 333 & -5.21 & -0.02 & -0.07 & $\mathbf{3 3 3 4 . 5 3}$ & $+0.60(10)$ \\
\hline & $E 2 U$ & 3392.42 & -7.33 & -0.00 & -0.27 & 3385.36 & $+1.56(20)$ \\
\hline & $3 C$ & 3502.82 & -7.95 & -0.00 & -0.19 & 3495.07 & $+1.05(10)$ \\
\hline & $3 B$ & 3605.64 & -2.98 & +0.44 & -3.52 & 3599 & $-1.12(25)$ \\
\hline & $3 A$ & 3654.93 & -3.73 & +0.45 & -3.47 & 3648.18 & $-1.64(10)$ \\
\hline \multirow[t]{12}{*}{ Xenon } & $M 2$ & 4214.66 & -6.88 & -0.26 & $\div 1.36$ & 4208.88 & $+1.32(20)$ \\
\hline & $3 G$ & 4220.07 & -6.74 & -0.26 & +1.36 & 4214.44 & $+1.17(20)$ \\
\hline & $E 2 L$ & 4310.17 & -5.61 & -0.04 & -0.23 & 4304.29 & $+0.98(20)$ \\
\hline & $E 2 M$ & 4404.55 & -6.49 & -0.03 & -0.11 & 4397.93 & $+0.87(30)$ \\
\hline & $3 F$ & 4552.50 & -11.29 & -0.18 & +1.39 & 4542.42 & $+1.12(20)$ \\
\hline & $3 D$ & 4566.37 & -8.79 & -0.07 & +0.23 & 4557.75 & $+0.05(20)$ \\
\hline & $E 2 U$ & 4738.43 & -11.91 & +0.01 & +0.39 & 4726.92 & $+1.50(50)$ \\
\hline & $3 C$ & 4868.79 & -12.81 & +0.02 & +0.20 & 4856.20 & $+1.21(20)$ \\
\hline & $3 B$ & 4961.57 & -4.84 & +0.84 & -5.98 & 4951.60 & $-2.40(40)$ \\
\hline & $3 A$ & 5053.18 & -6.09 & +0.86 & -5.92 & 5042.03 & $-2.10(20)$ \\
\hline & $E 2 S$ & 519 & -6 & 16 & -6.05 & 5181.22 & $-2.45(20)$ \\
\hline & $4 D$ & 5923.32 & -8.50 & 0.03 & 0.18 & 5914.61 & $+1.66[30)$ \\
\hline
\end{tabular}


TABLE IV continued.

\begin{tabular}{cccccccc}
\hline \hline Element & $K$ ey & $\begin{array}{c}\mathrm{E}_{\text {Coudomb }} \\
(\mathrm{eV})\end{array}$ & $\begin{array}{c}\mathrm{E}_{\text {Breit }}(\mathrm{eV}) \\
\text { Lanthanum }\end{array}$ & $\begin{array}{c}\mathrm{E}_{V P} \\
(\mathrm{eV})\end{array}$ & $\begin{array}{c}\mathrm{E}_{S E} \\
(\mathrm{eV})\end{array}$ & $\begin{array}{c}\mathrm{E}_{\text {ToTAL }} \\
(\mathrm{eV})\end{array}$ & $\begin{array}{c}\Delta \mathrm{E} \\
(\mathrm{eV})\end{array}$ \\
& $3 G$ & 4749.90 & -8.17 & -0.33 & +1.65 & 4743.04 & $+1.40(20)$ \\
& $E 2 L$ & 4852.97 & -6.63 & -0.05 & -0.32 & 4845.98 & $+1.08(20)$ \\
& $3 D$ & 5146.08 & -10.06 & -0.04 & -0.26 & 5135.73 & $+0.62(20)$ \\
& $3 F$ & 5184.21 & -14.04 & -0.27 & +2.17 & 5172.06 & $+1.48(20)$ \\
& $E 2 U$ & 5398.57 & -14.39 & +0.02 & +0.43 & 5384.62 & $+1.69(40)$ \\
& $3 A$ & 5737.04 & -7.37 & +1.11 & -7.29 & 5723.49 & $-2.28(40)$ \\
& $E 2 S$ & 5891.32 & -8.39 & +1.11 & -7.47 & 5876.58 & $-2.78(40)$ \\
Neodymium & $M 2$ & 5314.44 & -9.59 & -0.42 & +1.97 & 5306.39 & $+1.52(25)$ \\
& $3 G$ & 5320.62 & -9.38 & -0.42 & +1.97 & 5312.79 & $+1.38(25)$ \\
& $3 D$ & 5766.89 & -11.66 & -0.04 & -0.45 & 5734.75 & $+0.48(40)$ \\
& $3 F$ & 5859.14 & -16.99 & -0.35 & +2.67 & 5844.46 & $+2.17(40)$ \\
Europium & $M 2$ & 5907.56 & -11.15 & -0.54 & +2.35 & 5898.22 & $+1.69(60)$ \\
& $3 G$ & 5914.14 & -10.90 & -0.54 & +2.35 & 5905.05 & $+1.80(60)$ \\
\hline \hline
\end{tabular}


TABLE $V$. Therretical energies of the transitions $3 A, 3 B$, and E2S. The energies are obtained from optimal level calculations which take into account interactions with states $\left(2 s^{2} 2 p^{4} 3 p 3 d\right)_{J_{-}}$in the case of transitions 3.1 and $3 B$, and interactions with states $\left(2 s^{2}-2 p^{4} 3 d 3 d d_{J=2}\right.$ in the case of transition E2S. $\mathrm{E}_{\mathrm{CK}}$ is the fractirn of $\mathrm{E}_{\text {TOTAL }}$ which arises from (super) Coster-Kronig fluctuations.

\begin{tabular}{|c|c|c|c|c|c|c|}
\hline \multirow[b]{2}{*}{ Elcruent } & \multicolumn{2}{|c|}{$3 B$} & \multicolumn{2}{|c|}{$\overline{3.1}$} & \multicolumn{2}{|c|}{$E 2 S$} \\
\hline & $\begin{array}{c}\mathrm{E}_{\text {TOT } A L} \\
(\mathrm{cl})\end{array}$ & $\begin{array}{l}E_{C K} \\
(\mathrm{Cl})\end{array}$ & $\begin{array}{c}E_{T(t) A L} \\
(\mathrm{cl})\end{array}$ & $\begin{array}{l}F_{C K K} \\
\left(r 1^{\prime}\right)\end{array}$ & $\begin{array}{c}E_{\text {ToTAL }} \\
(\mathrm{FI})\end{array}$ & $\begin{array}{l}\mathrm{E}_{C K} \\
(\mathrm{cl})\end{array}$ \\
\hline Silver & 3597.69 & -1.90 & $3 6 \longdiv { 4 6 . 2 8 }$ & (1.90) & & \\
\hline fenon & +949.69 & -1.91 & 5040.12 & -1.91 & $3180: 32$ & -0.90 \\
\hline Lanlhanum & & & 5721.57 & -1.92 & 5875.68 & 0.90 \\
\hline
\end{tabular}




\section{Figures}

FIG. 1. Minimum central electron temperature necessary to observe $x$-ray transitions in neonlike ions of atomic number $Z$ with the PLT high-resolution Bragg-crystal spectrometer. The line-averaged electron density in each case was $1 \times 10^{13} \mathrm{~cm}^{-3}$ : The solid line is drawn as a visual aid only.

FIG. 2. Overview of the spectra observed in the wavelength range $2.00-3.00$ $\AA$ showing the location of the $x$-ray transitions in neonlike xenon, lanthanum, neodymium, and europium with respect to the location of various hydrogen- and heliumlike reference lines. The notation used to label the neonlike transitions is that of Table I. No measurements were made in the interval $2.19-2.29 \AA$ (shaded region).

FIG. 3. Spectrum of the $3 s_{1 / 2} \rightarrow 2 p_{3 / 2}$ transitions, labelled $3 G$ and $M 2$, in $\mathrm{Nd}^{50+}$. The spectrum was obtained with the PLT high-resolution spectrometer. Also seen are satellites due to $3 s_{1 / 2} \rightarrow 2 p_{5 / 2}$ transitions in lower charge states of neodymium. The data have been accumulated from 33 PLT discharges. The background is due to the bremsstrahlung and recombination continuum.

FIG. 4. Spectrum of the transition $3 s_{1 / 2} \rightarrow 2 p_{1 / 2}$, labelled $3 F$, and $3 d_{5 / 2} \rightarrow$ $2 p_{3 / 2}$, labelled $3 D$, in $\mathrm{Nd}^{50+}$. The data have been accumulated from 13 PLT discharges. For elements with $Z \geq 55$ the wavelength of line $3 F$ is shorter than the wavelength of line $3 D$ as a result of the relativistic splitting of the $2 p_{3 / 2}^{5}$ and $2 p_{1 / 2}^{5}$ core levels. The increased line width of line $3 D$ compared to line $3 F$ is due to a diminished resolution of the spectrometer.

FIG. 5. Comparison of measured and theoretical energies for transitions of the type: (a) $3 s_{1 / 2} \rightarrow 2 p_{3 / 2}$ and $3 d, 3 p \rightarrow 2 s$; (b) $3 s_{1 / 2} \rightarrow 2 p_{1 / 2}$; (c) $3 d, 4 d \rightarrow 2 p$; and (d) $3 p \rightarrow 2 p$. The theoretical values were calculated in the extended average level approach, except transitions $3 C$ and $3 D$ which were calculated in the optimum level approach. The solid lines are drawn as a visual aid only. 


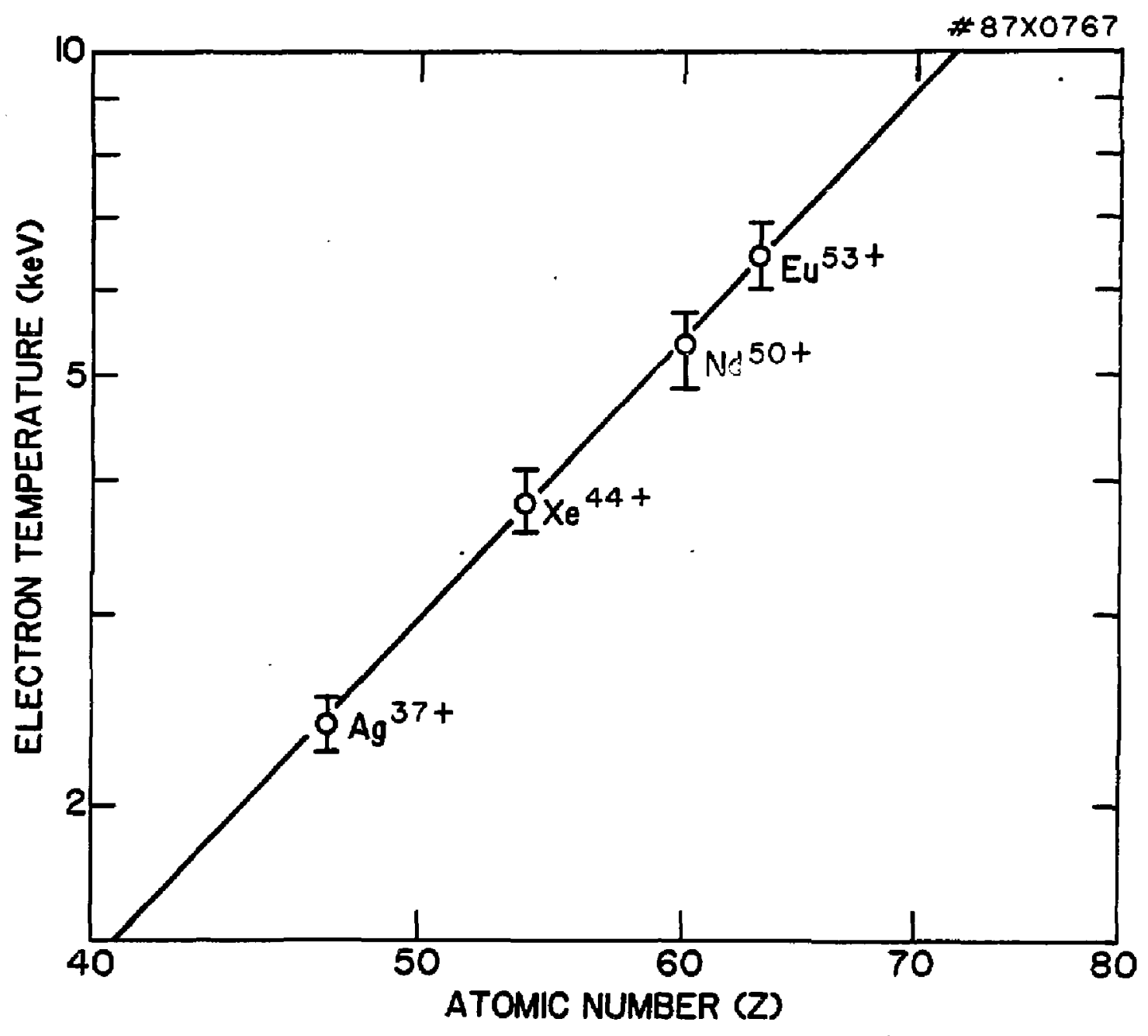

Fig. 1 
*87x0622

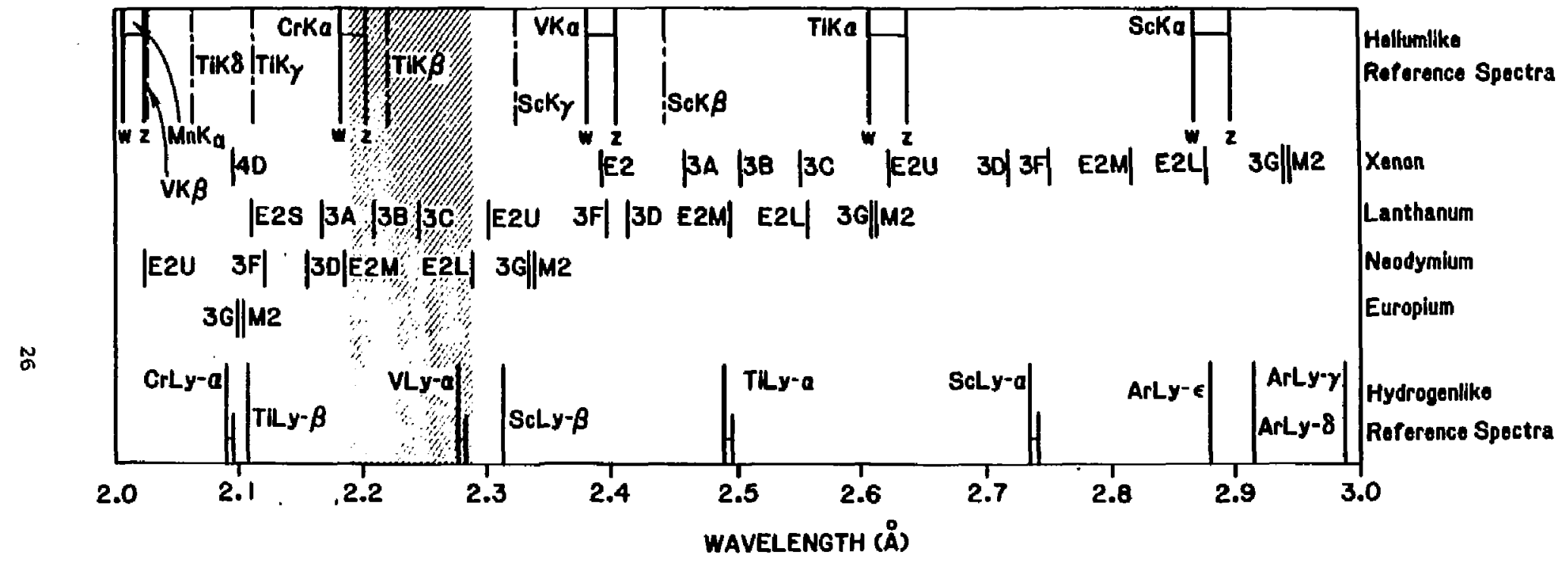

Fig. 2 
\#87X0140

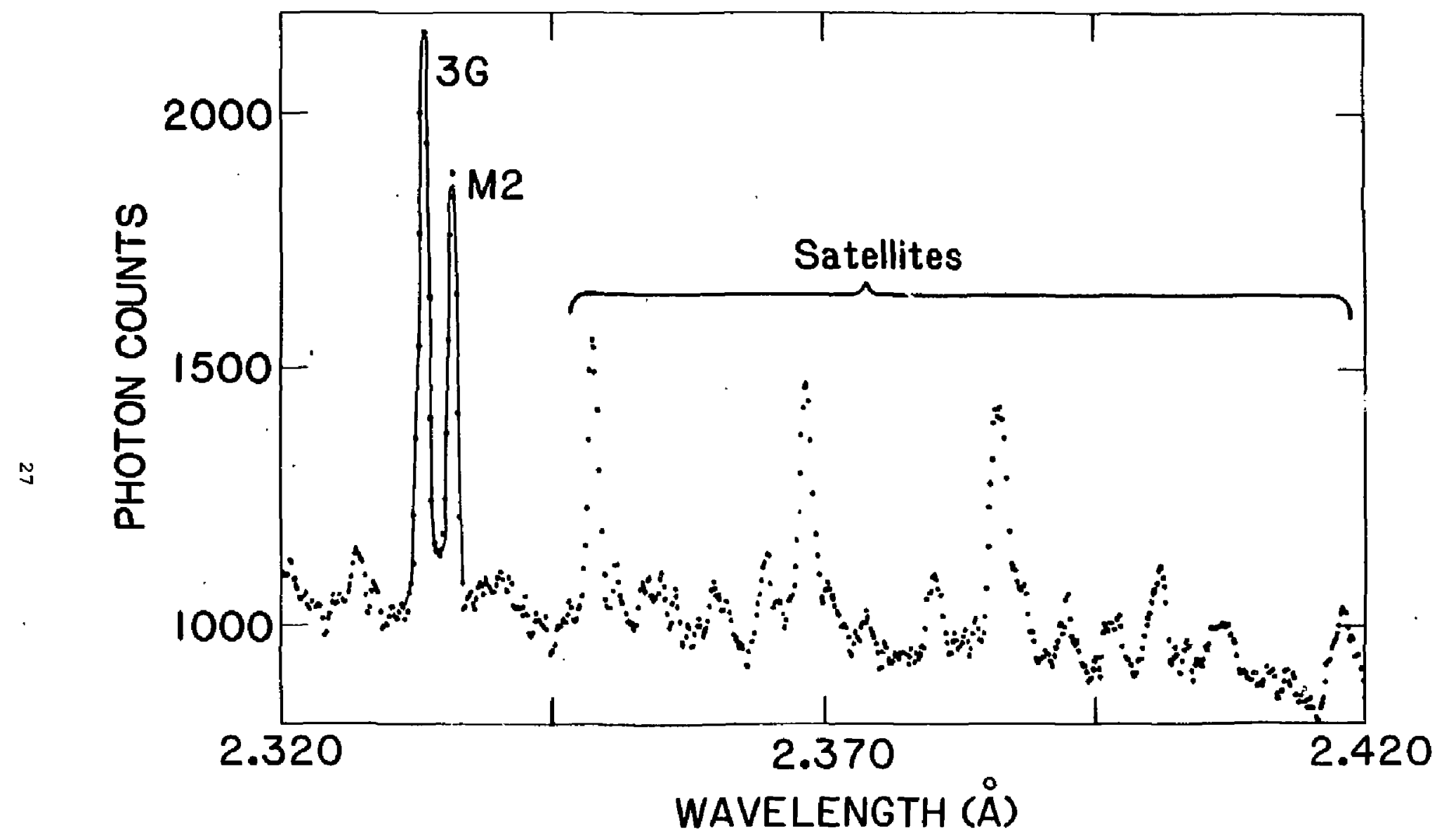




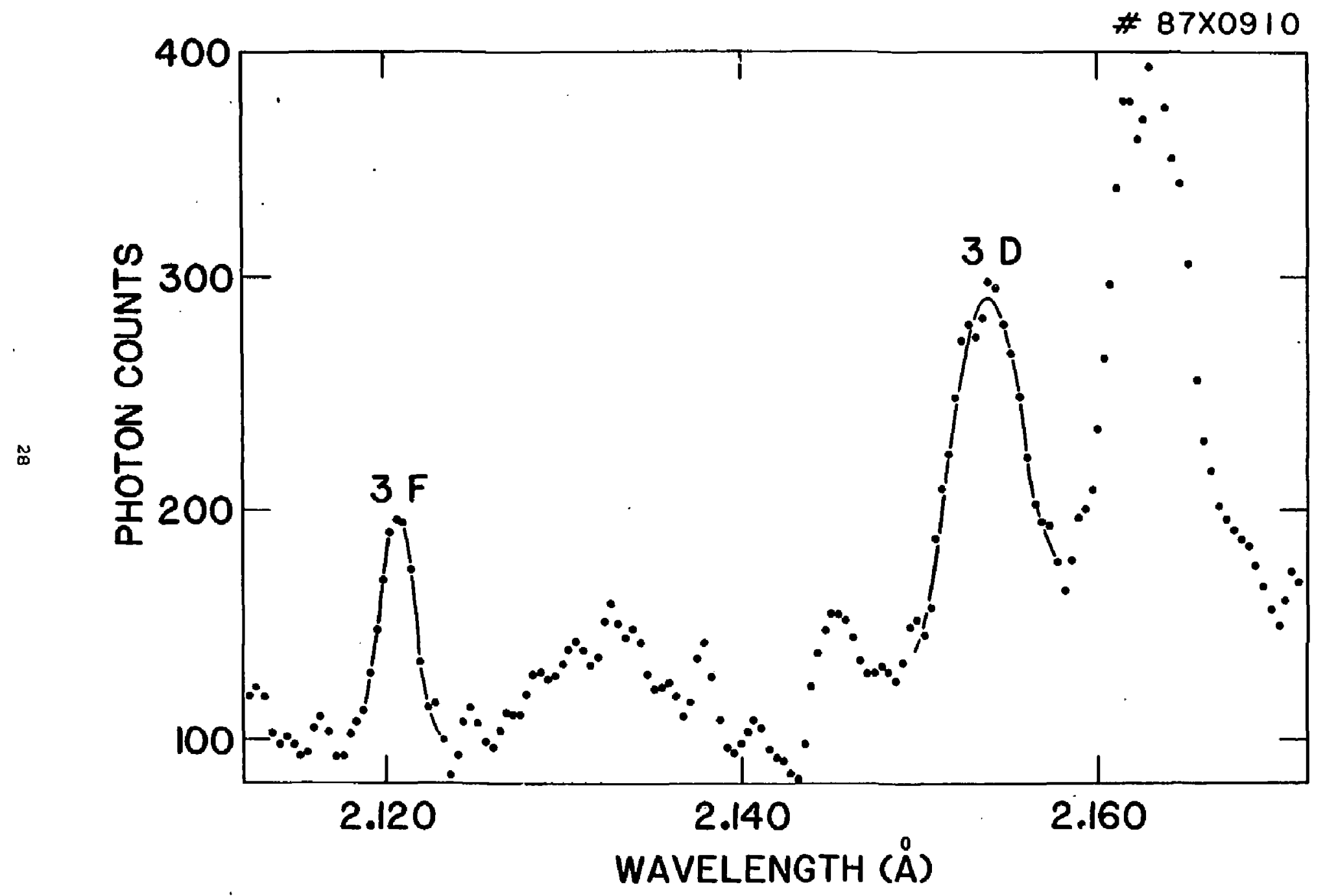

pig. 4 


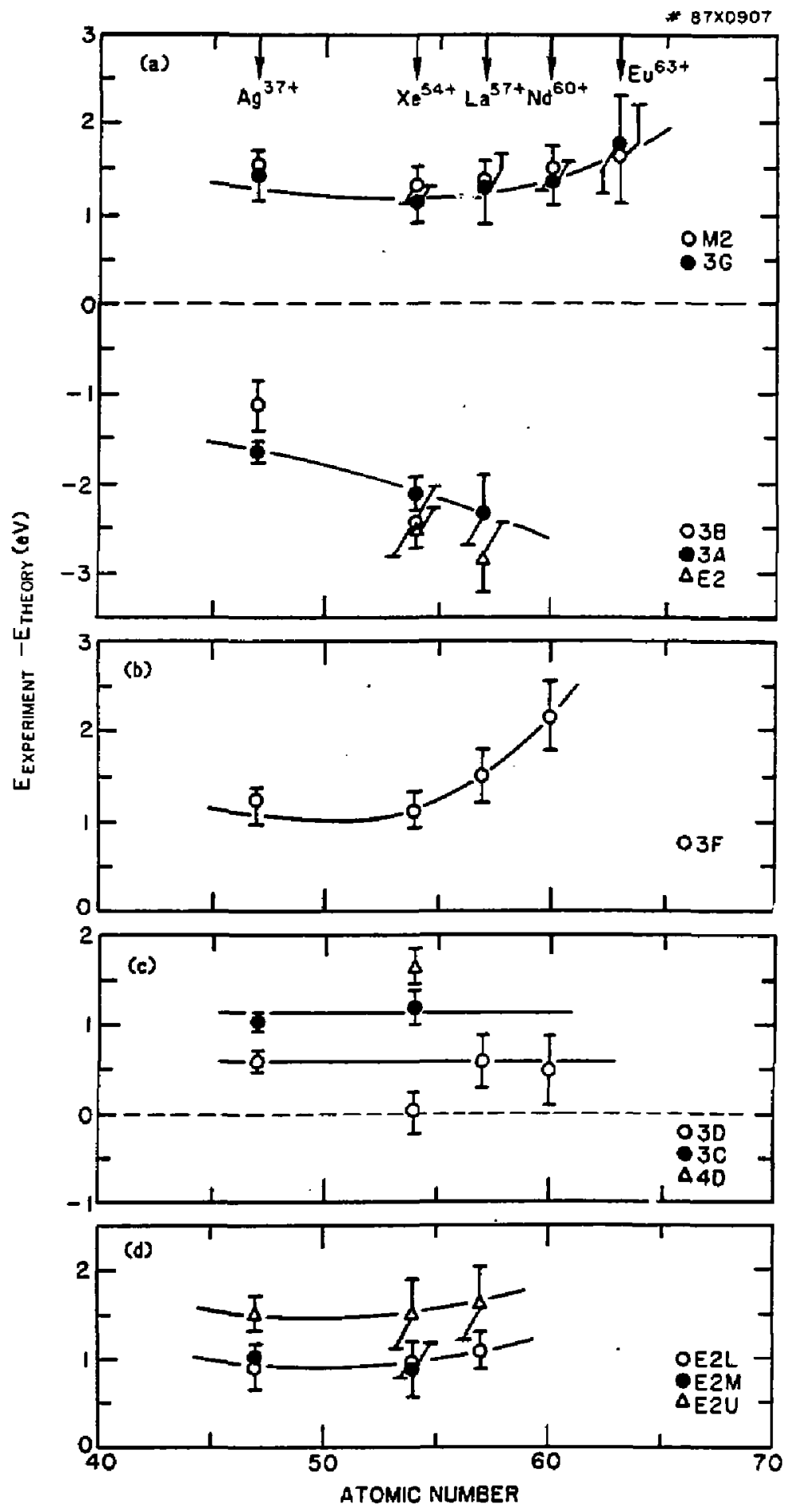

Fig. 5 


\section{EXTERNAL DISTRIBUTION IN ADDITION TO UC-20}

Dr. Frank J. Paoloni, Lniv of Wollongong, AuSTRALIA

Prof. M.H. Grennan, Univ Sydney, AustRaLIA

Plasma Researeh Lab., Australian Nat. Univ., AUSTRALIA

Prof. I.R. Jones, FI inders Univ., Australia

Prof. F. Cap, Inst Theo Phys, Austria

Prot. M. Heindler, Institut t ur Theoretische Physik, AUstria

M. Goossens, Astronomiseh Instituut, BELGIUM

Ecole Rayale Militaire, Lab de Phys Plasmas, BELGIUM

Comission-European, Dg-XII Fusion Prog, BELGIUM

Praf. R. Boucique, Laboratorium voor Natuurkunde, BELGIUM

Dr. P.H. Sakanaka, Instituta Fisicd, BRAZIL

Instituto de Pesquisas EsDacias i-INPE, BRAZIL

Documents oftice, Atomic Energy of Canada Limited, CANADA

Dr. M.P. Bachynski, MPB Technologies, Ine., CANADA

Dr. H.M. Skarsgard, University of Saskatethewan, CANAOA

Or. H. Barnard, University of British Columbia, CANACA

Prot. \. Teichmann, Univ. of Montreal, CANADA

Prof, S,R. Sreenivasan, Un i versity of Calgary. CANADA

Prot. Tudor W. Jehnston, IMAS-Energie, CANADA

Dr. C.R. James, Univ, of Alberta, CANADA

Dr. Peter Lukac, Komenskeho Univ, CzECHOSLOVAKIA

The Librarian, Culhan Laboratory, ENGLAND

The Librarian, Rutherford Applaton Laboratory, ENGLAND

Mrs. S.A. Hutehinson, JET Library. ENGLAND

C. Houttet, Lab. de Phrsique des Millieux lonisés, fRAnCE

3. Radet, CEN/CADARACHE - lat 506, FRANCE

Univ. of loannina, Library of Physics Dept. GREECE

Dr. Ton Mual, Acadeny Bibliographic Sar., hoNG kONG

Preprint Library, Hungarian Acadeny of Sciences, HUNenRY

Dr. B. Dasgupta, Saha Inst of Nucl. Phys., IND|A

Dr. P. Kar, institute for Plasne Research, INDIA

Dr. Philip Rosenau, Israel Inst. Teen, ISAAEL

Librarian, Int', Ctr Theo Phys, ITALY

Prof. G. Rostagni. Univ Di Padova, ITALY

Miss Clelia de Palo, Assoc EuRaton-ENEA, ITALY

Biblioteca, instituto di fisica del Plasna, ITALY

Dr. H. Yamato, Toshiba Res \& Dev, JAPAN

Prof. I. Kawakami, Atomic Energy Res. Institute, JAPAN

Prof. Kyoji Nishikawa, Univ of Hiroshima, JAPAN

Direc. Dept. Large Tokanak Res. JAERI, JAPAN

Prof. Sotoshi itoh, Kyushu University, JAPAN

Research Info Center, Nagoya Univarsity, JAPAN

Prof. 5. Tanaka, Kyoto University, JAPAN

Library, Kyoto University, JAPAN

Prot. Nobuyuki Inoue, University of Tokyo, JAPAN

5. Mor $i$, JAERI, JAPAN

Librarian, Korea Advanced Energy Res. Institute, KOREA

Prof. 0.1. Choi. Adv. Inst Sci \& Tech, KoreA

Prot. 日.S. Liley, University of Waikato, NEW ZEALAND

Institute of Plasma Physics, PEOPLE'S REPUELIC OF CHINA

Librarian, Institute of Phys., PECPLE'S REPUBLIC OF CHINA

Library, Tsing Hug University, PEOPLE'S REPUBLIC OF CHINA
Z. Li, Southwest Inst. Physics, PEOPLE'S REPU日L IC OF CHINA

Prof. J.A.C. Cabral, Inst Super ior Tecnico, PORTUGAL

Dr. Octavian Petrus, AL I CUZA University, ROMANIA

Dr. Johan de Villiers, Fusion studies, AEC, SO AFrICA

Prof. M,A. Hellberg, University of Natal, SO AFRlCA

C.I.E.M.A.T., Fusion Div. Library, SPAIN

Dr. Lennart Stenflo, University of UMMEA, SWEDEN

Library, Royal I nst Tech, SwEDEN

Prof. Hans Wlithelmson, Chalmers Univ Tech, SWEDEN

Centre Phys des Plasmas, Ecole Polytech Fed, SWITZERLAND

Bibliotheek, Fom-Inst Voor PIasma-Fysica, THE NETHERLANDS

Dr. O.D. Ryutov, Siberian Acad Sci. USSR

Dr, G.A. Eliseev, Kurchator Institute, USSR

Or. V,A. Glukhikh, Inst Electrophysical ADoaratus, USSR

Or. V.T. Tolok, Inst. Phys. Tech. USSR

Or. L.M, Kovrizhnykn, Institute Gen. Physics, USSR

Nuclear Res. Establishment, Julich Lto., N. GERMANY

Bibliothak, Inst. Fur plasmatorschung, W. GERMANY

Dr. K. Schindler, Ruhr Universitat Bochum, W. GERMANY

ASDEX Reading Rm, IPP/Max-PIanck-Institut fur

Plasmaphysik, W. GERMANY

Librarian, Max-PIanck Institut, H, GEAMANY

Prof. R.K. Janev, Inst Phys, YugosLavia 